\title{
Thermal Emissivity of a Nuclear Graphite as a Function of Its Oxidation Degree (2) - Effect of Surface Structural Changes -
}

\author{
Seung-Kuk Seo ${ }^{1}$, Jae-Seung Roh ${ }^{1, \uparrow}$, Eung-Seon Kim², Se-Hwan Chi' ${ }^{2}$, Suk Hwan Kim ${ }^{1}$ \\ and Sang Woo Lee ${ }^{1}$
}

\author{
${ }^{1}$ School of Advanced Materials and System Engineering, Kumoh National Institute of Technology, Gumi, Gyeongbuk 730-701 \\ ${ }^{2}$ Korea Atomic Energy Research Institute (KAERI), Yuseong-gu, Daejeon 305-353 \\ ‘e-mail: jsroh@kumoh.ac.kr \\ (Received July 13, 2009; Accepted September 23, 2009)
}

\begin{abstract}
Thermal emissivity of nuclear graphite was measured with its oxidation degree. Commercial nuclear graphites (IG-110, PECA, IG-430, and NBG-18) have been used as samples. Concave on graphites surface increased as its oxidation degree increased, and $\mathrm{R}$ value ( $\mathrm{Id} / \mathrm{Ig}$ ) of the graphites decreased as the oxidation degree increased. The thermal emissivity increased depending on the decrease of the $\mathrm{R}(\mathrm{Id} / \mathrm{Ig})$ value through Raman spectroscopy analysis. It was determined that the thermal emissivity was influenced by the crystallinity of the nuclear graphite.
\end{abstract}

Keywords : Nuclear graphite, Oxidation, Emissivity, Microstructure, Crystallinity

\section{Introduction}

Graphite and carbon materials are well accepted as nuclear power or energy materials and their main usages are being expanded to coating materials for heat releases in electronic components of electronic devices or LED. In nuclear reactors, especially, graphite acts as a moderator and reflector as well as a major structural component mainly due to its excellent thermal, physical, chemical, and mechanical properties as well as high moderating ratio [1].

In view of the safety of VHTR (very high temperature reactor) radiative core cooling capability in case of an accident (for example, primary coolant pipe rupture), the thermal emissivity of graphite grades is an important property to be considered for material selection. Since the heat generated from the nuclear fuel is continuously delivered to the outside of the pressure container by the graphite's thermal conductivity as well. In addition the VHTR is operated at the high temperature of $900^{\circ} \mathrm{C}$ or higher, the non-active Ar or He gases are used for the vapor flowing to prevent oxidation of graphite [1]. It may, however, generate critical defects such as oxidation of the graphite when an extremely small amount of impure substance exists in the non-active gases during accident $[2,3]$. Therefore the thermal emissivity of the graphite is very important for the drastic heat release. However there were very little studies done on the thermal emissivity of the nuclear graphite. Especially, there is little reported on the relationship between thermal emissivity and changes of crystallinity by oxidation of graphite.

On the other hand, the oxidation reaction of carbon based materials take place at the active sites preferentially. In addition to the active sites, the other factors affecting characteristics of oxidation reaction include microstructural characteristics related to the inhomogeneity occurring in the process of manufacture of the carbon materials [4-8].

Artificial graphite is composed of binder, filler and crushed filler. Easily graphitized materials such as petroleum coke are commonly chosen as filler material in the manufacture of nuclear graphite [9]. The petroleum coke as a filler is expected to be fully graphitized after heat treatment at $3000^{\circ} \mathrm{C}$. On the other hand, different binder pitches have been used during nuclear graphite fabrication by different manufacturers. It was shown that the oxidation of nuclear graphite take place at binder phase preferentially to the coarse filler particles [10,11].

Many researchers have tried to interpret structural parameters of carbon materials via several analyzing techniques such as X-ray diffraction (XRD), high resolution transmission electron microscopy (HRTEM), high resolution scanning electron microscopy (HRSEM), scanning tunneling microscopy (STM) and Raman spectroscopy. Some researchers have reported articles using Raman apparatus for structural analysis of the carbon fiber [12-15]. Koradatos reported that Raman spectroscopy could be used to evaluate the crystallinity of the produced CNTs. The spectrum shows two 
bands at $1360 \mathrm{~cm}^{-1}$ (D-band) and $1589 \mathrm{~cm}^{-1}$ (G-band), respectively. The high intensity of the $\mathrm{G}$ as compared with the D-band indicates a high degree of crystallinity [16]. And Schenze, Fisher, and Brendler reported the crystallinity of cellulose I by Raman spectroscopy. They said Raman crystallinity values of cellulose I formulated by $\mathrm{Xc}=(\mathrm{Ic} /$ Ic+Ia) 100 were developed [17].

Recently, we reported the results of structural changes of high modulus carbon fibers and isotropic carbon fibers due to oxidation using Raman spectroscopy $[18,19]$. Also we reported the relationship between emissivity and porosity changed by oxidation of nuclear graphite [20]. In this study the crystallinity of commercial nuclear graphite prepared by oxidation have been observed using laser Raman spectroscopy, and compared with microstructure.

\section{Experimental}

\subsection{Specimens, oxidation processes and thermal emissivity measurement}

The specimens used in this study are commercial nuclear graphites (IG-110, PCEA, IG-430, and NBG-18). The basic properties of nuclear graphites and methods for oxidation processes and thermal emissivity measurement were early reported [20].

\subsection{Microstructure observation}

The change in microstructures of the specimen by oxidation reaction was observed by the scanning electron microscope (SEM) and magnification was 500 times. The SEM observations were conducted on $60^{\circ}$ tilted specimens to see surface morphologies more clearly.

\subsection{Crystallinity using Raman spectroscopy}

Raman spectroscopy was used to analyze the change of the crystallinity by oxidation of graphite. The Raman spectrometry (inVia System, Renishaw, France) uses the Ar laser $(514.5 \mathrm{~nm})$ as the light source. A 500X magnification microscope was used to select a point to focus laser beam spot on the graphites surface. The spot size of laser beam was about $1 \mu \mathrm{m}$ in diameter. Extended scans from 500 to $2000 \mathrm{~cm}^{-1}$ were performed to obtain the 1st-order Raman bands of the graphites.

Highly ordered graphite shows only one band in the region of 1100 and $1700 \mathrm{~cm}^{-1}$ and shows the 2nd-order features between 2400 and $3300 \mathrm{~cm}^{-1}$. The Raman spectra change significantly for disordered carbons and show D band at around $1350 \mathrm{~cm}^{-1}$. Therefore the characteristic Raman spectra for synthetic graphite show peaks at around $1350 \mathrm{~cm}^{-1}$ for disordered carbon (D band) and $1580 \mathrm{~cm}^{-1}$ for
Table 1. Results of the Thermal Emissivity

\begin{tabular}{cccccc}
\hline $\begin{array}{c}\text { Wt. loss } \\
(\%)\end{array}$ & $\begin{array}{c}\text { Temperature } \\
\left({ }^{\circ} \mathrm{C}\right)\end{array}$ & IG-110 & PCEA & IG-430 & NBG-18 \\
\hline $0 \%$ & & 0.681 & 0.731 & 0.682 & 0.737 \\
& 200 & 0.601 & 0.663 & 0.626 & 0.627 \\
& 300 & 0.585 & 0.645 & 0.657 & 0.609 \\
& 400 & 0.582 & 0.587 & 0.646 & 0.538 \\
& 500 & 0.558 & 0.596 & 0.647 & 0.649 \\
\hline $5 \%$ & 100 & 0.786 & 0.861 & 0.815 & 0.847 \\
& 200 & 0.776 & 0.797 & 0.805 & 0.777 \\
& 300 & 0.771 & 0.795 & 0.816 & 0.729 \\
& 400 & 0.759 & 0.681 & 0.818 & 0.681 \\
& 500 & 0.666 & 0.691 & 0.755 & 0.738 \\
\hline $10 \%$ & 100 & 0.835 & 0.866 & 0.854 & 0.890 \\
& 200 & 0.783 & 0.850 & 0.812 & 0.834 \\
& 300 & 0.775 & 0.803 & 0.819 & 0.756 \\
& 400 & 0.764 & 0.718 & 0.824 & 0.694 \\
& 500 & 0.675 & 0.696 & 0.800 & 0.738 \\
\hline
\end{tabular}

graphitized carbon ( $G$ band) [21-23]. The degree of graphitization may be estimated by examining the Raman spectra for a specimen. Relative intensity between $G$ and D bands could be changed by heat treatments, crystallite size of the disordered carbon, and crystallinity.

We introduce the intensity ratio(R) values from the 1 storder Raman bands that calculated by $R=I d / I g$. The average value of crystallinity was achieved after measuring at 5 different positions on specimen surface following oxidation proceeds.

\section{Results and Discussion}

\subsection{Thermal emissivity}

As reported already the emissivity measurement result following the oxidation degree is summarized in Table 1 [20]. The thermal emissivity showed an increasing tendency as the porosity increased. Therefore it could be said that increases of porosity resulting from oxidation affect increases of thermal emissivity. Also the specimen with the highest thermal emissivity in Table 1 is $10 \%$ oxidized NBG18 measured at $100^{\circ} \mathrm{C}$, but the decreasing rate may be higher depending on measuring temperatures.

\subsection{Surface microstructure}

The images taken at a magnification of x500 with the change of the surface structure following the oxidation degree of the nuclear graphite are shown at Fig. 1 4. The concave on the surface increases as the oxidation degree increases. It means that the concave increases because the amorphous area is oxidized preferentially. 

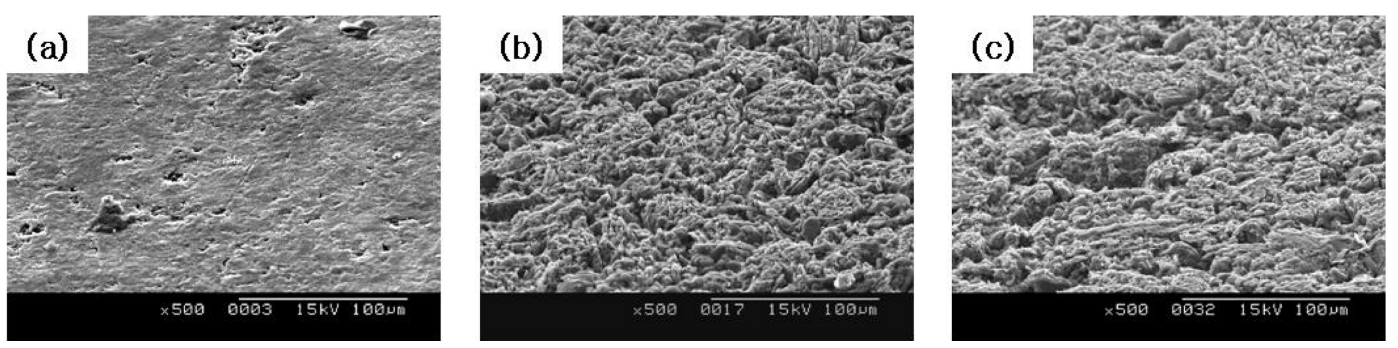

Fig. 1. Surface morphologies of IG-110; (a) $0 \%$, (b) 5\%, (c) $10 \%$ wt. loss.
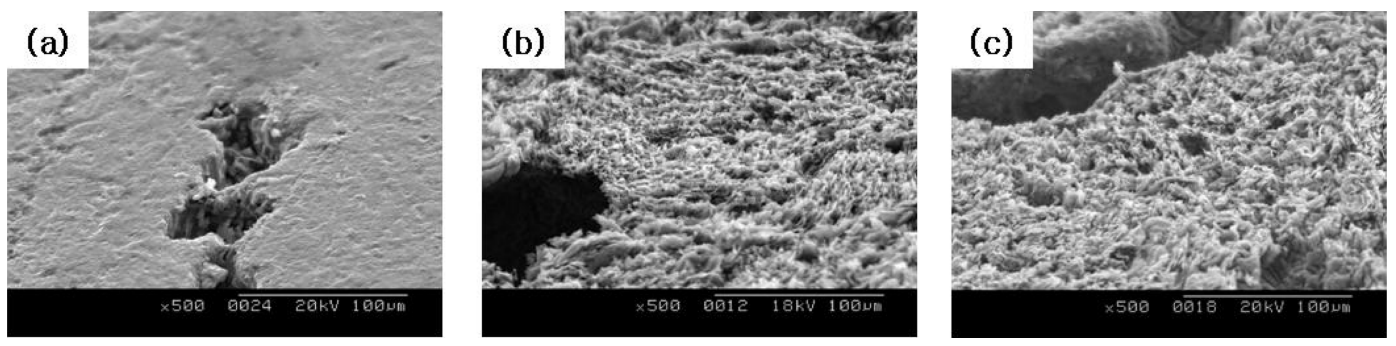

Fig. 2. Surface morphlogies of PCEA; (a) $0 \%$, (b) $5 \%$, (c) $10 \%$ wt. loss.
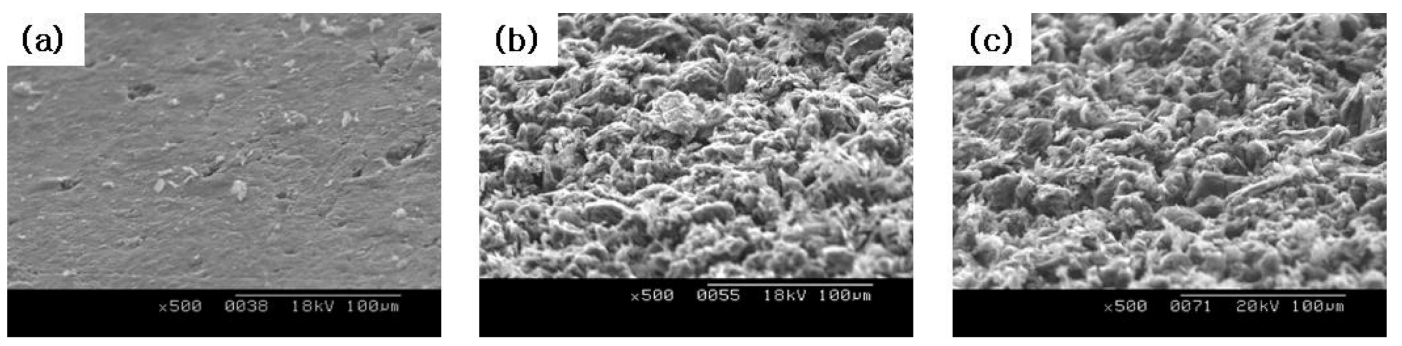

Fig. 3. Surface morphologies of IG-430; (a) $0 \%$, (b) 5\%, (c) $10 \%$ wt. loss.
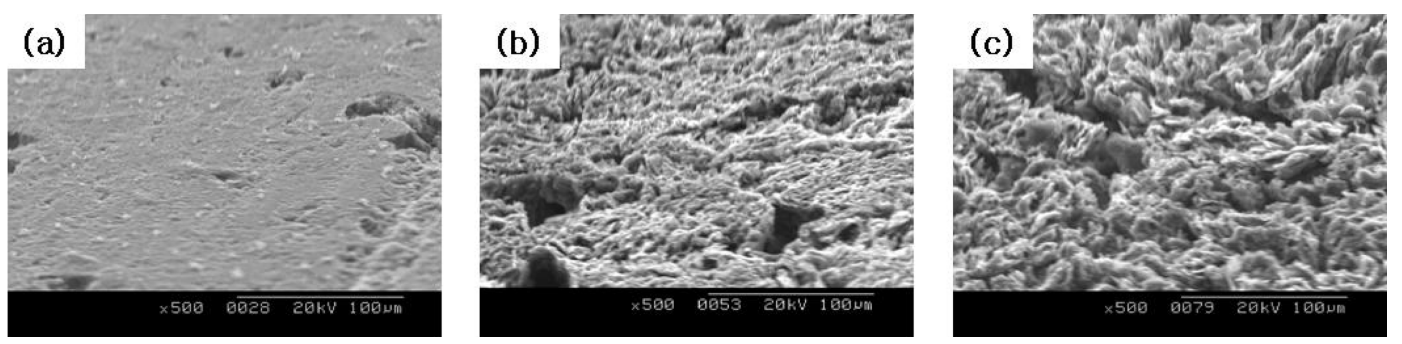

Fig. 4. Surface morphologies of NBG-18; (a) $0 \%$, (b) 5\%, (c) $10 \%$ wt. loss.

\subsection{Crystallinity}

The change in the degree of intensity ratio(R) values following the oxidation degree is measured and it is shown in Table 2 and Fig. 5. To get the $\mathrm{R}$ value, five measurements are averaged for each specimen.

In Fig. 3 and Table 2 there were not significant shift exist between the each positions of the D- (around $1357 \mathrm{~cm}^{-1}$ ) and G-bands (around $1581 \mathrm{~cm}^{-1}$ ). The oxidation processes have almost no effect on the band positions.

Intensity ratios $(\mathrm{R}=\mathrm{Id} / \mathrm{Ig})$ of $\mathrm{D}$ - and $\mathrm{G}$-band of the graphites were varying in the range of 0.08 to 0.25 . The $\mathrm{R}$
Table 2. Results of Intensity Ratio(R) Values

\begin{tabular}{ccccc}
\hline Wt. loss (\%) & IG-110 & PCEA & IG-430 & NBG-18 \\
\hline $0 \%$ & 0.25 & 0.16 & 0.13 & 0.15 \\
$5 \%$ & 0.14 & 0.12 & 0.06 & 0.13 \\
$10 \%$ & 0.08 & 0.11 & 0.08 & 0.08 \\
\hline
\end{tabular}

values decrease with degrees of oxidation.

It could be explained that the reason of non-shifting of Raman bands of graphite is caused by well ordered structure of graphites. The increase in crystallinity resulted from Raman analysis after oxidation was attributed to the 

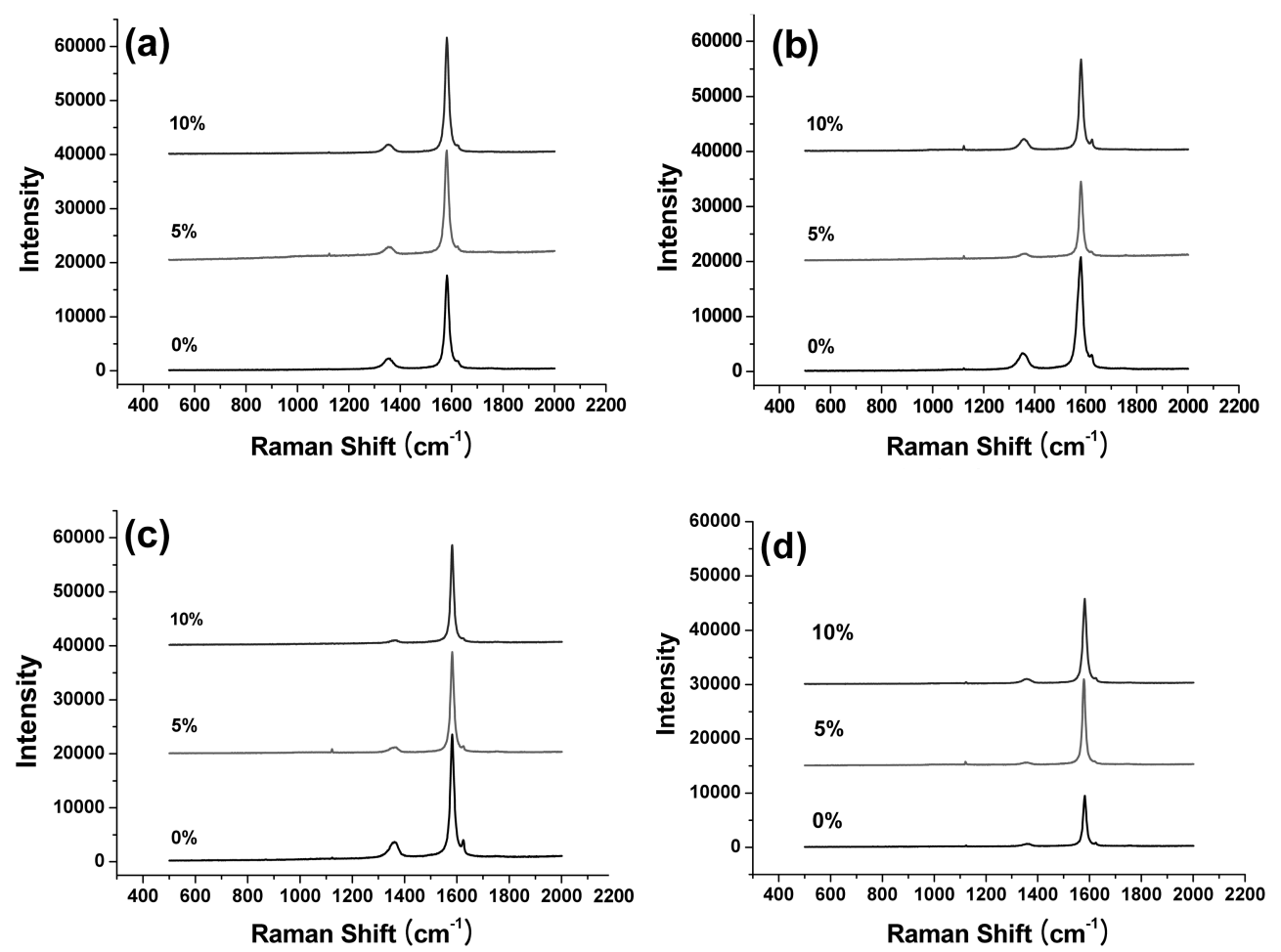

Fig. 5. Raman spectra as a function of oxidation of nuclear graphite; (a) IG-110, (b) PCEA, (c) IG-430, (d) NBG-18.

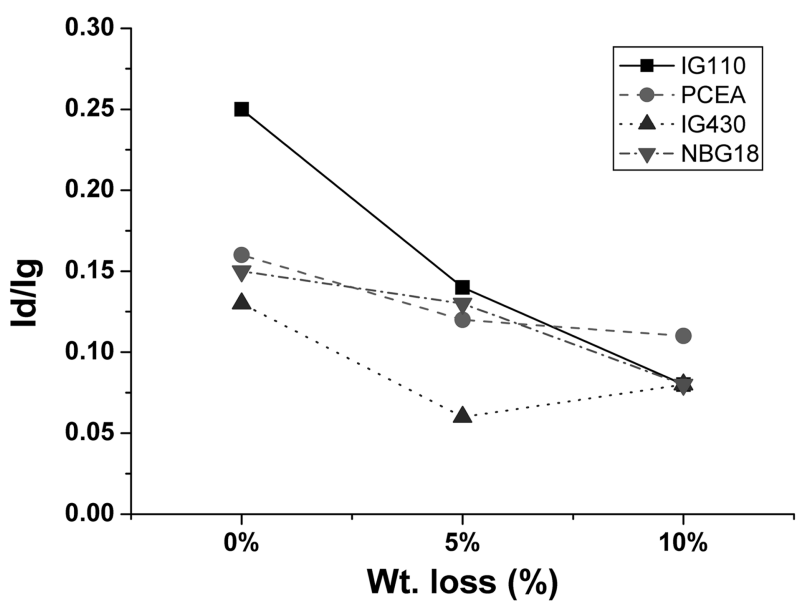

Fig. 6. Results of $\mathrm{Id} / \mathrm{Ig}$ as a function of oxidation degrees by Raman spectroscopy.

selective oxidation of binder [10,11].

The $\mathrm{R}$ value changes as a function of the oxidation degree is summarized in Fig. 6. As the oxidation degree increases, the Id/Ig value decreases and it implies the increase of the crystallinity. It means that the binder with low crystallinity compared to the filler phase is oxidized first. Therefore, as the Raman result, the overall crystallinity of the specimen increase after the oxidation.

The relationship of all of the $\mathrm{R}$ value and thermal emissivity is demonstrated on Fig. 7. As the crystallinity

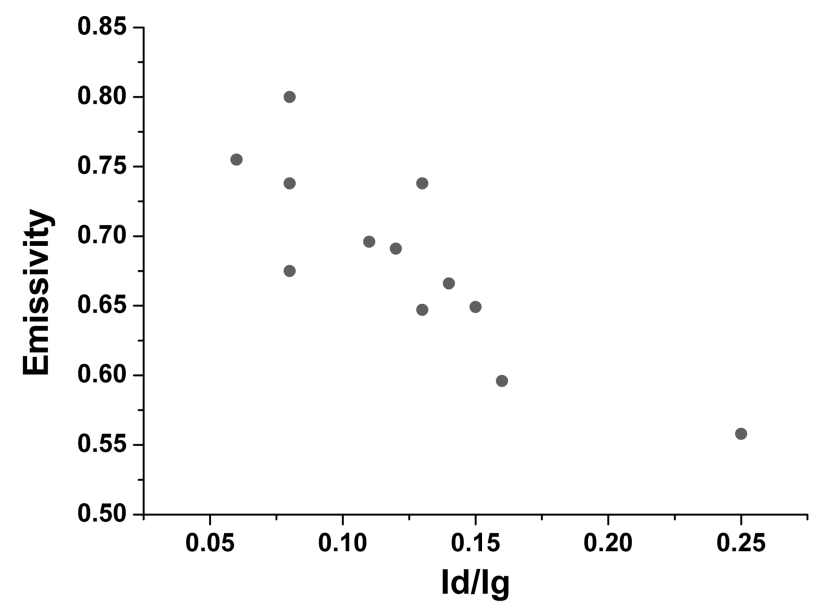

Fig. 7. Relationship of the R value and emissivity.

increases, the thermal emissivity also has the tendency of increasing as well. Therefore the emissivity revealed that increases in the crystallinity due to oxidation were responsible for the increase in emissivity after oxidation.

\section{Conclusion}

Thermal emissivities of nuclear graphites following changes in oxidation degrees were studied. The graphite was oxidized in air flow of $5 \mathrm{l} / \mathrm{min}$ at $600^{\circ} \mathrm{C}$ using a furnace, and the thermal emissivities were measured using an infrared 
spectrum analyzer. Microstructure and surface structure (crystallinity) following oxidation degrees were compared with thermal emissivity.

The concave on the surface increases as the oxidation degree increases. It was regarded that the concave increased because the amorphous area was oxidized preferentially. The $\mathrm{R}$ value (Id/Ig) of the nuclear graphite decreases as the oxidation degree increases, and the thermal emissivity increases depending on the decrease of the $\mathrm{R}$ value through Raman spectroscopy analysis.

Therefore it could be concluded that the crystallinity increase following oxidation degree of the nuclear graphite and the thermal emissivity increase would be similar tendency. It was determined that the thermal emissivity was influenced by the crystallinity of the nuclear graphite.

\section{References}

[1] Moormann, R.; Hinssen, H. K.; Kühn, K. Nuclear Engineering and Design 2004, 227, 281.

[2] Kurumada, A.; Oku, T.; Harada, K.; Kawamata, K.; Sato, S.; Hiraoka, T.; McEaney, B. Carbon 1997, 35, 1157.

[3] Idaho National Engineering \& Environmental Laboratory, "Very High Temperature Gas Cooled Reactor Systems", 2002 Winter ANS Meeting, Washington, D.C. \& T. Chunhe and G. Jie, J. Nuclear Materials 1995, 224, 103.

[4] Mahajan, O. P.; Yarzab R.; Walker Jr. P. L. Fuel 1978, 57, 643.

[5] Sanchez, A. R.; Elguezabal, A. A.; Torre Saenz, L. L. Carbon, 2001, 39, 1367.

[6] Kasaoka, S.; Sakata, Y.; Kayano, S.; Masuoka, Y. Int. Chem. Eng. 1983, 23, 477.
[7] Hu, Y. Q.; Nikzat, H.; Nawata, M.; Kobayashi, N.; Hasatani, M. Fuel 2001, 80, 2111.

[8] Rafsanjani, H. H.; Jashidi, E.; Rostam-Abadi, M. Carbon 2002, 40, 1167.

[9] Eatherly, W. P.; Piper, E. L. "Nuclear Graphite", ed. Nightingale R. E., Academic Press, New York and London, 1962, 21.

[10] Babout, L.; Mummery, P. M.; Marrow, T. J.; Tzelepi, A.; Withers, P. J. Carbon 2005, 43, 765.

[11] Wen, K.Y. ; Marrow, T. J. ; Marsden, B.J. Carbon 2008 , 46,62

[12] Sharma, A.; Kyotani, T.; Tomita, A. Carbon 2000, 38, 1977.

[13] Kovalevski, V. V.; Buseck, P. R.; Cowley, J. M. Carbon 2001, 39, 243.

[14] Senneca, O.; Salatino, P.; Masi, S. Fuel 1998, 77, 1483.

[15] Busyin, R. M.; Rouzaud, J. N.; Ross, J. V. Carbon 1995, 33,679 .

[16] Kordatosa, A. D.; Vlasopoulosa, S.; Strikosa, A.; Ntziounia, S.; Gavela, S.; Trasobaresb, V.; Kasselouri-Rigopouloua. Electrochemica Acta 2009, 54, 2466.

[17] Schenze, K.; Fischer, S.; Brendler, E. Cellulose 2005 , 12, 223.

[18] Roh, J. S. Carbon letters 2008, 9, 127.

[19] Roh, J. S.; Kim, S. h. Carbon Letters 2009, 10, 1.

[20] Seo, S. K.; Roh, J. S.; Kim, E. S.; Chi, S. H.; Kim, S. H.; Lee, S. W. Carbon letters, in press.

[21] Hardwick, L. J.; Novak, P.; Buqa, H. Solid State Ionics 2006, 177, 2801.

[22] Hirai, T.; Compan, J.; Niwase, K.; Linke, J. J. Nuclear Materials 2008, 373, 119.

[23] Perraki, M.; Proyer, A.; Mposkos, E.; Kaindl, R.; Hoinkes, G. Earth and Planetary Science Letters 2006, 241, 672. 